\title{
Deaths following trivial trauma
}

Rathnaweera RHAI*

Department of Forensic Medicine, Faculty of Medicine, Karapitiya, Galle, Sri Lanka

*Corresponding author: Tel: 0094-772969060. E-mail address: ajithrathnaweera@yahoo.com

MLJSL.Vol 3. No 1. March. pp 25-28

\begin{abstract}
:
Introduction

It is often an assessment of the circumstances, in addition to the autopsy findings, which decides a court's attitude to the relationship of trauma to disease.
\end{abstract}

\section{Case report 1}

Sixty year old male, was assaulted by his son with clubs. Later he was found unconscious and on admission to hospital, he was found to be dead.

Autopsy findings:

There were non-fatal blunt force injuries. Coronary arteries were occluded in significant percentages and myocardial fibrosis was noted.

Histopathology revealed patchy fibrosis of the myocardium.

\section{Case report 2}

Fifty four year old male was assaulted by a group of people and on the following day he was found unconscious on the ground. On admission to the hospital, he was found to be dead.

Autopsy findings:

Non-fatal blunt force injuries were present. His coronary arteries were occluded in significant percentages and myocardial fibrosis was noted.

Histopathology revealed patchy fibrosis of the myocardium.

\section{Case report 3}

Forty five year old male was assaulted by his neighbour and developed tightening type of chest pain. At the hospital, he was found to have developed a myocardial infarction. He died two days later.

Autopsy findings:

No external injuries were present. Right coronary artery was $100 \%$ occluded with a thrombus.

Histopathology revealed acute myocardial infarction.

\section{Conclusions}

Although the forensic pathologist plays an important role in finding the cause of death following trivial trauma, the contribution in determining the manner can be limited especially those due to sudden cardiac death. Decision on culpability of the assailant is based on mens rea or the guilty mind which is the mental element of the offence. The mere simple non grievous nature of these injures does not necessarily mean that assailants were not having an intention of causing death.

Key words: Sudden death, trivial trauma, Ischaemic heart disease, Myocardial fibrosis, arrythmia 


\section{Introduction:}

Virtually all forensic experts deal not only with criminal, suspicious, accidental and suicide deaths, but they are also confronted with a wide range of deaths where a significant natural element is revealed at autopsy. The assaulted victim who dies suddenly or unexpectedly from a myocardial infarction during or immediately succeeding the receipt of some non-fatal injuries, or otherwise suffers a clinically unexplained death, can pose far greater difficulties over causation than a gun-shot or a stabbing [1]. Forensic experts are often required to give an opinion on the cause of death and its medico-legal interpretation in cases where an individual dies after receiving non-fatal injuries and at autopsy is discovered to have had a natural disease that alone could have caused death. The significance of this varies in different countries depending on the local laws relating to death in cases of trivial trauma associated with natural disease [2].

Diagnosis of sudden cardiac death $(S C D)$ is a crucial aspect in forensic practice because of (1) misdiagnosis of extrinsic death as SCD, (2) underreporting of unusual (unnatural) death, (3) difficulty in diagnosis by autopsy, histology, and death-scene investigation, (4) difficulty to judge the contribution of accident, violence, psychological stress, over-work, and medical malpractice [3]. Forensic pathologists must precisely diagnose the proximate cause of death and determine the contribution of extrinsic and intrinsic factors, thereby showing fair proof for the legal responsibility of the deceased and concerned party. Where a man who has had no previous cardiac symptoms drops dead immediately after some assault, the court is more likely to assume an association than with a diagnosed patient with a cardiac illness, who has been hovering on the brink of heart dysfunction for a long time before the traumatic event [4].

\section{Case report 1}

An apparently well, 60 year old male, had an argument followed by a quarrel with one of his sons. He was assaulted with clubs and pushed to the floor. After that he was chased away from the house. In the evening, 3-4 hours after the incident, he was found lying unconscious at a nearby bush by his daughter. Then he was immediately brought to the Hospital but was found to be dead on admission.

\section{Autopsy findings:}

There were tram line contusions over the back and impact abrasions over the back of the right hand. But these injuries were found to be nonfatal as there was no underlying tissue damage. The heart appeared enlarged and weighed 470gms. Left ventricular hypertrophy was present. Almost the entire right coronary artery was approximately $50 \%$ obstructed due to eccentric uncomplicated atheroma. The left main coronary artery and the proximal portion of the anterior descending branch (i.e. one centimeter below the bifurcation) were $80 \%$ obstructed by eccentric uncomplicated atheroma with some calcification. Left ventricular apical slices showed concentric hypertrophy of the myocardium. The thickness of the left ventricle was $2.5 \mathrm{~cm}$.

Cut section of the myocardium revealed an area of transmural fibrosis of $4 \mathrm{~cm} \times 3 \mathrm{~cm}$ on the anterior wall and septal wall of the left ventricle. Histopathology revealed patchy fibrosis of the myocardium.

The cause of death was ascertained as Ischaemic heart disease in a man with non fatal blunt force injuries.

\section{Case report 2}

A Fifty four year old male (known patient with ischaemic heart disease) was assaulted by a group of people around $11.00 \mathrm{pm}$. On the following day around 6.30am, he was found unconscious on the ground. On admission to the hospital, he was found to be dead.

\section{Autopsy findings:}

There were multiple abrasions and contusions over the face, left knee joint, and over the back of the left elbow. All these were non fatal injuries with no underlying structures involved. The heart was enlarged and weighed $550 \mathrm{gms}$. Left ventricular hypertrophy was present. His left 
anterior descending artery was occluded more than $90 \%$ and left circumflex artery was occluded more than $75 \%$. The right coronary artery was occluded $25 \%$. Cut section of the myocardium revealed an area of transmural fibrosis of $2 \mathrm{~cm} \mathrm{x}$ $6 \mathrm{~cm}$ on the anterior wall of the left ventricle.

Histopathology revealed patchy fibrosis of the myocardium.

The cause of death was ascertained as Ischaemic heart disease in a man with non fatal blunt force injuries.

\section{Case report 3}

Forty five year old male was assaulted by his neighbour around $1.30 \mathrm{pm}$. He had developed difficulty in breathing and tightening type of chest pain around $2.00 \mathrm{pm}$ and he was admitted to the hospital. He was found to have ST elevation and diagnosed as myocardial infarction. He died two days later.

\section{Autopsy findings:}

There was a contusion over the lateral aspect of the middle $1 / 3$ rd of the right upper arm and an abrasion over the front of the right knee joint. These injuries were found to be nonfatal as there was no underlying tissue damage. The heart appeared enlarged and weighed $530 \mathrm{gms}$. Left ventricular hypertrophy was present. Right coronary artery was $100 \%$ occluded with a thrombus. Histopathology revealed acute myocardial infarction.

The cause of death was ascertained as acute myocardial infarction in a man with non fatal blunt force injuries.

\section{Discussion}

Of the cases of sudden death investigated by the Forensic Pathologist, after adequate examination, about $75 \%$ of total number will be found to be deaths from natural causes [5]. Many of these deaths are sudden, unexpected, clinically unexplained or obscure[6]. Though it is not an unusual occurrence for a man to die suddenly following emotional disturbance and trivial trauma with pre-existing heart disease, the forensic pathologist is faced with a dilemma of explaining to courts and relatives how the former condition affected the latter resulting in death [7].

The Forensic Pathologist determines the cause of death based on the known facts concerning the circumstances leading up to the death in conjunction with the findings at the autopsy and the laboratory tests. In all three cases, even though blunt force injuries were found, they were superficial injuries without any damage to underlying vital structures. Injuries were not sufficient by themselves to cause death but death has occurred. The possibility of death following vagal inhibition due to trauma on vulnerable areas is another possibility but in these cases, nobody died immediately following the assault. In case of vagal inhibition, death would have been immediate.

However, the contribution to death from minor trauma and emotional disturbances associated with verbal arguments and pain cannot be excluded in these cases. The stress of a verbal argument as well as any minor traumatic incident can lead to increased secretion of catecholamine which in turn can result in increased heart rate leading to fatal arrhythmia[7 ,8, 9]. Possible pro-arrhythmic mechanisms associated with emotional and physical stress include alterations in autonomic tone manifested by decreased vagal and increased sympathetic components; this in turn increases the overall susceptibility to ventricular fibrillation especially in individuals with preexisting cardiac disease [10]. In the first two cases, there were pre-existing scarring and in the third case, there was evidence of myocardial infarction. In all three cases, there was myocardial hypertrophy as well. Myocardial hypertrophy, scarring and infarctions are identified risk factors for sudden fatal arrhythmia [7]. However, there are no specific macroscopic or microscopic features to identify a case of arrhythmia and it is most of the time a diagnosis of exclusion. In our setup, sometimes excluding all the other possible pathological and toxicological causes can be a difficulty with the available facilities. 
In the third case, there was no evidence of pre existing heart disease according to the history given by the wife of the diseased. Other than myocardial hypertrophy, no evidence of pre existing heart disease was found at the autopsy as well. After considering the history and autopsy findings, physical and emotional stress may have contributed to the development of the myocardial infarction. Proving a cause effect relationship is not straightforward but the possibility cannot be excluded. Timing of the myocardial infarction is very important in this case but with available facilities it is very difficult.

\section{Conclusions}

Although the forensic pathologist plays an important role in finding the cause of the death following trivial trauma, the contribution in determining the manner can be limited especially those due to sudden cardiac death. Decision on culpability of the assailant is based on mens rea or the guilty mind which is the mental element of the offence. The mere simple non grievous nature of these injures does not necessarily mean that assailants were not having an intention of causing death. Therefore, most of the times the courts expect the forensic pathologist to give an opinion on the contribution of the trivial trauma to the aggravation of the natural illness, which will be a challenge to prove beyond reasonable doubt.

\section{References}

1. Kohli A, Mishra K. Trivial trauma, heart disease and medico-legal interpretation of death. Med Sci Law. 2008 Jan;48(1):72-4.

2. Vij K. Heart disease vis-à-vis trauma. Med Sci Law. 1999 Oct;39(4):345-8.
3. Chowaniec C, Chowaniec M, Nowak A, Kobek M. [Sudden cardiac death--difficulties in passing a medico-legal opinion for a civil or insurance claim]. Arch Med Sadowej Kryminol. 2007 Jan-Mar;57(1):72-7.

4. Kumar V, San KP, Idwan A, Shah N, Hajar S, Norkahfi M. A study of sudden natural deaths in medico legal autopsies in University Malaya Medical Centre (UMMC), Kuala Lumpur. Journal of Forensic and Legal Medicine. 2007;14(3):151-154.

5. Knight $B$, Saukko $P$, Knights Forensic Pathology . Edward Arnold. 3rd ed.2004.p 492 - 493.

6. Spitz WU, Spitz and Fisher's Medico-legal investigation of Death. Charles C. Thomas. 4th ed.2004. p 302.

7. Kitulwatte I.D.G. A case of sudden death following minor intentional trauma; Pathologist's contribution in the decision on the manner of death. Sri Lanka Journal of Forensic Medicine, Science \& Law-May 2012-Vol.3 No.1

8. Kirchhof $P$, Klimas J, Fabritz L, Zwiener $M$, Jones LR, Schäfers $M$, Hermann S, Boknik $P$, Schmitz W, Breithardt G, Kirchhefer $U$, Neumann J., Stress and high heart rate provoke ventricular tachycardia in mice expressing triadin, J Mol Cell Cardiol. 2007 May;42(5):962-71.

9. DO Williams, TA Bass, $\mathrm{H}$ Gewirtz and AS Most, Adaptation to the stress of tachycardia in patients with coronary artery disease: insight into the mechanism of the warm-up phenomenon, Circulation 1985;71;687-692

10. Christine M. Albert, Claudia U. Chae, Kathryn M. Rexrode, JoAnn E. Manson and Ichiro Kawachi, Phobic Anxiety and Risk of Coronary Heart Disease and Sudden Cardiac Death Among Women,Circulation, 2005;111;480-487 